\title{
Decommissioning Alcoa's First Bauxite Mine in the Jarrah Forest of Western Australia - Cradle to Grave
}

\author{
C. Grant Alcoa World Alumina Australia, Huntly Mine, Australia
}

\section{$1 \quad$ INTRODUCTION}

Alcoa World Alumina Australia currently operates two bauxite mines at Willowdale and Huntly in the Darling Range of south-western Western Australia, 80-140 km south of Perth (Figure 1). Huntly is the largest bauxite mine in the world, producing over 20 million $t$ of ore every year. The bauxite from the two mines is processed into alumina at three refineries at Kwinana, Pinjarra and Wagerup. The alumina is then shipped interstate and overseas for smelting to produce aluminium.

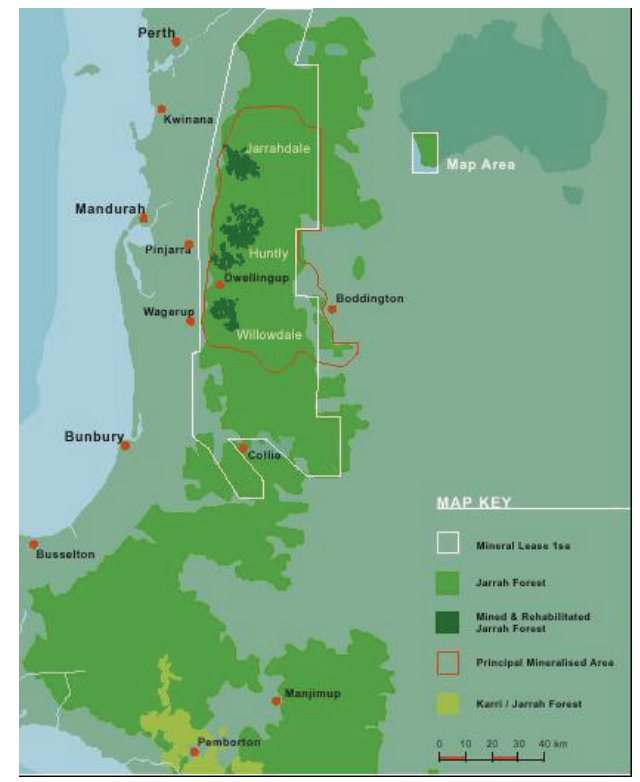

Figure $1 \quad$ Location of Alcoa's mines, refineries and ports in Western Australia

Alcoa's bauxite mining operations commenced in 1963 at the Jarrahdale Mine. The mine commenced operations at the No. 1 site which is now a popular picnic spot called Langford Park. In 1970, the crushing plant was moved to the No. 2 site where it was located until the mine ceased production in late 1998. During this time, 168 million $\mathrm{t}$ of bauxite were mined. In May 2001, rehabilitation of the Jarrahdale Mine was completed finalising the closure of this site. This was the first mine that Alcoa had closed and fully rehabilitated in Western Australia. The company had set a challenging target for the site by wanting the Jarrahdale mine closure to attain benchmark rehabilitation for surface mining worldwide producing an ecologically sustainable area that meets agreed completion criteria. The specific objectives of the mine closure plan were:

- Maintain a high focus on environmental and safety standards.

- All rehabilitation achieves the completion criteria for its era.

- Planning for the potential future use of the mine or infrastructure will involve the neighbouring community and other interested parties and be approved by Alcoa's regulators.

- The site is left in a condition which is safe, self sustaining and suitable for future land-uses.

- The amount of waste disposed to landfill is minimised by recycling and reuse. 
- The final rehabilitated site is considered a role model by the mining industry.

- The site is liability free when relinquished to the State Government or utilised by another body.

The objective of this paper is to provide a summary of the major steps that were involved in the closure of the Jarrahdale Mine. This included consultation with government and the community, removal of all infrastructure, removal of a dam and numerous stream crossings, removal of all contaminated materials, rehabilitation of all disturbed areas to agreed completion criteria, review and remediation (if necessary) of older rehabilitation areas and development of long-term management plans to allow relinquishment back to the State Government. Key activities relating to each of these steps are detailed below following background information on Alcoa's bauxite mining operations.

\section{BACKGROUND TO ALCOA'S MINING OPERATIONS}

Mining takes place in the jarrah (Eucalyptus marginata) forest contained within the water supply catchment of Perth and the surrounding region. The jarrah forest has high conservation value, is the basis of a major sawmilling industry and is widely used for recreational pursuits. The jarrah forest has a diverse flora estimated to include more than 780 species, and is part of the South-western Botanical District, acknowledged as one of the biodiversity hotspots of the world. The forest, with these multiple uses, is managed by the State Government authorities. The uniqueness of the jarrah forest and its proximity to Perth present an enormous challenge in terms of environmental management and restoration.

The bauxite ore is relatively shallow, averaging 4 to $5 \mathrm{~m}$ deep in extent, and is usually located less than one metre below the soil surface. The mine pits range in size from a single hectare to tens of hectares. Alcoa has been restoring its bauxite mines since 1966, and approximately 550 ha are currently mined and restored annually. The total area cleared for mining and its associated infrastructure at Jarrahdale was 4090 ha. All areas cleared for mining and infrastructure are restored. After timber harvest, the mining sequence involves clearing the remaining vegetation, removing the soil, blasting the cemented bauxite layer, removing and crushing the bauxite and transporting it to the refineries.

The restoration process starts with shaping the mine pit, returning the soil and ripping to $1.5 \mathrm{~m}$ deep using a bulldozer with a winged tine. Logs and rocks are returned to provide habitat for native fauna. Seeds of local plants are spread, and nursery-grown plants are planted for species where seed is not a viable method of establishment. A fertiliser mix is then applied in late winter or early spring using a helicopter. Establishment of vegetative cover is rapid (Figure 2). A more detailed description of the restoration process is provided elsewhere (e.g. Ward et al., 1996; Gardner, 2001).
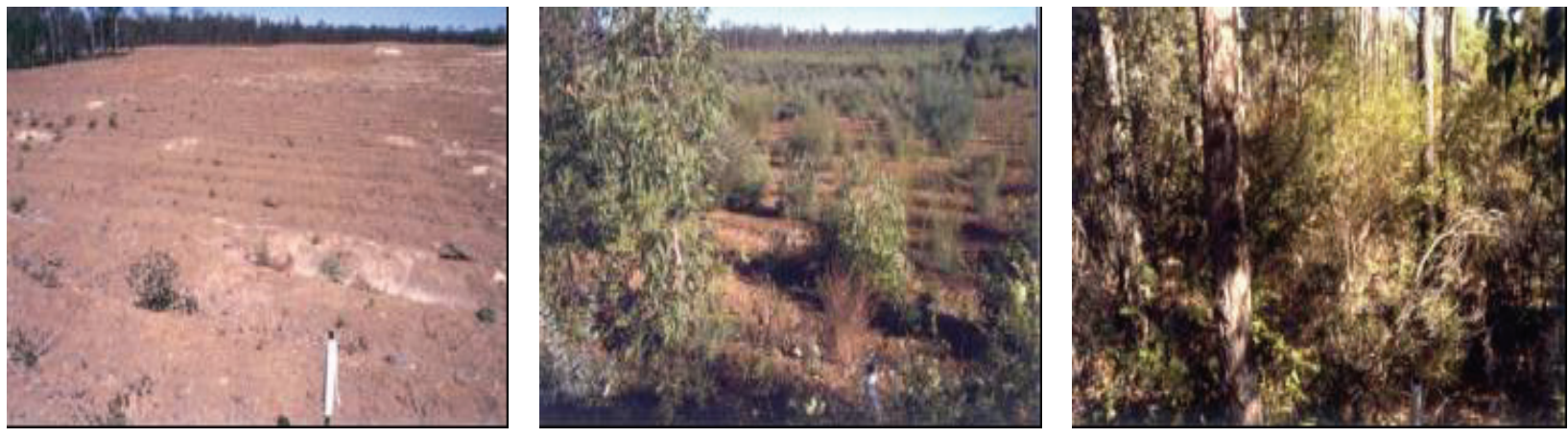

Figure 2 Time sequence photos of one restored site at 1 (left), 2 (middle) and 13 (right) years of age

\section{CONSULTATION WITH GOVERNMENT AND THE COMMUNITY}

The Mining and Management Program Liaison Group (MMPLG) was established in 1979 as a condition of the environmental approval of the Wagerup Alumina Project and the Alumina Refinery (Wagerup) Agreement Act of 1978. The group is comprised of senior public servants from the Department of Industry and Resources, Department of Conservation and Land Management, Department of Environment, Water Corporation and Department of Water. The function of the group is to review Alcoa's mining and 
management programs for all locations and to provide advice to the Minister for State Development, regarding approval of those plans, giving specific consideration to social and environmental issues.

In February 1997, a plan for the closure of the Jarrahdale mine was submitted to the Minister for State Development. The Minister formally agreed that proposed changes to the Jarrahdale Mine be assessed by the MMPLG as part of the Mining and Management Program (MMP) to be submitted that year. As part of the closure approval, the Minister required Alcoa to consult with community groups and government departments to determine if the mine infrastructure or mine area could be utilised by another party.

The mine is situated in State forest managed by the Department of Conservation and Land Management (CALM) for multiple land-uses including drinking water catchment, timber production, recreation and conservation. Alcoa made a commitment to the MMPLG not to encourage any community expectations that were clearly incompatible with current multiple land-use objectives for State Forest as detailed in the CALM Forest Management Plan. The first step was to identify any government, education, community groups or organisations that may have a requirement for the use of the workshops, buildings or open areas on site. The main factor in identifying potential future users of the site was their ability, both in resources and funds, to maintain the infrastructure and associated services such as the waste water treatment plant, sewage plant, potable water system and waste disposal costs. A number of proposals were considered including using the railway line to establish a tourist loop rail line in the Jarrahdale area, developing the water supply dam into a wetland and picnic area, use of mine pits as a driver training area, use of the buildings for artists and craft people, use of the site for a mine training school and use of the haul road system to link two existing highways.

By the end of 1999, no formal submissions had been made to Alcoa, though discussions were continuing with the Main Roads Department (MRD) about the use of the haul road system. Thus, a decision was made by management and supported by the MMPLG to rehabilitate all open areas at the mine to a jarrah forest ecosystem. This included the removal of Chandler Dam, the water supply for the mine site. As talks were ongoing, rehabilitation of the hauls roads of interest to the MRD was delayed. Eventually, when no decision was forthcoming, rehabilitation of these roads was completed during the final rehabilitation season.

When the site submitted a more comprehensive closure plan to the MMPLG for approval in April 1999, it contained options for both leaving infrastructure in place for use by another party or the removal of infrastructure and the full rehabilitation of the site. This allowed the site to develop a comprehensive plan of how the infrastructure would be removed. Developing this plan, even though it may not be required, meant that if the infrastructure was to be removed it could commence as soon as a decision was made, ensuring that rehabilitation process was not held up. As the decommissioning of the site progressed, an updated plan was presented to the MMPLG annually. The plan was therefore a live document that was updated to also describe activities as they were undertaken. This process worked well and allowed the decommissioning plan to achieve its target of having the site fully rehabilitated by May 2001.

\section{REMOVAL OF INFRASTRUCTURE}

All infrastructure such as buildings, workshops, fuel bays, power lines, water pipes and pumps, the sewage and waste water treatment plant was dismantled and removed from site (Figure 3). Two auctions were held at the mine, one for the crushing plant and another for the workshops, stores and other minor buildings. An Environmental, Health and Safety Inspection was undertaken in each area prior to any dismantling or demolition work to ensure safety and environmental issues were identified and managed. For all dismantled or demolished infrastructure, the following objectives were developed:

- All infrastructure to be removed down to bare earth to allow for rehabilitation.

- Underground services and pipes to be removed where possible.

- Power and water to all services to be isolated prior to commencing any dismantling or demolition activities.

- All material that to be reused or recycled will be salvaged where possible.

- All material that cannot be salvaged to be disposed of according to existing regulations or guidelines. 
The Jarrahdale Mine was regulated under the Mine Safety and Inspections Act (1994). As the mine was no longer operational, Alcoa requested clearance from the Department of Industry and Resources (DoIR) indicating that its requirements relating to mine safety had been met. Following a site inspection, a letter was received from DoIR in 2004 outlining that all infrastructure had been removed and the site had been left in a safe condition (Figure 4).

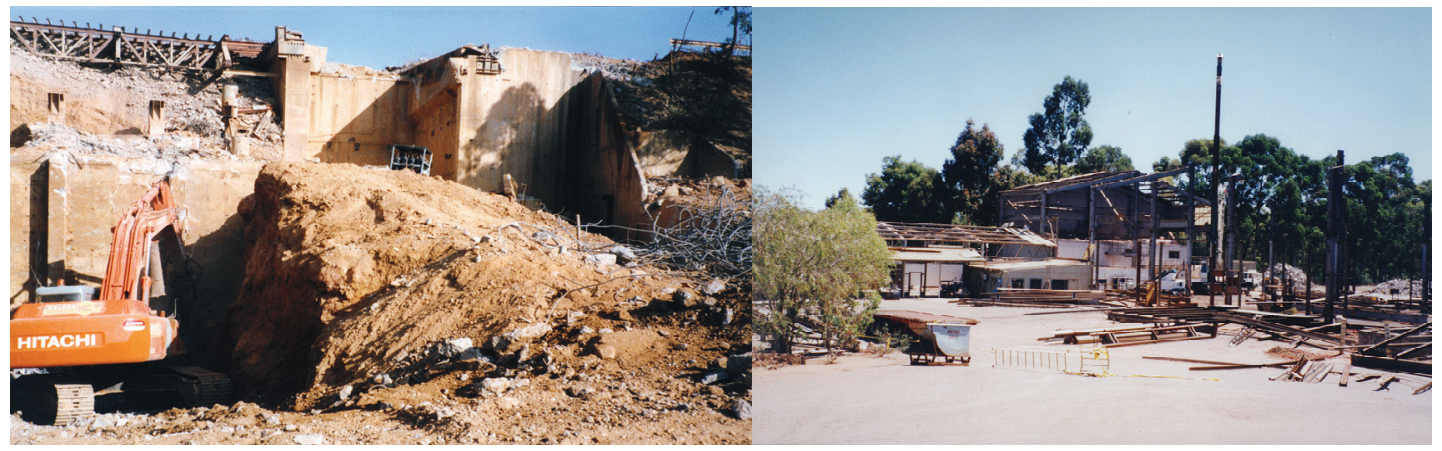

Figure 3 Removal of the crusher footings (left) and dismantling of the workshops (right)

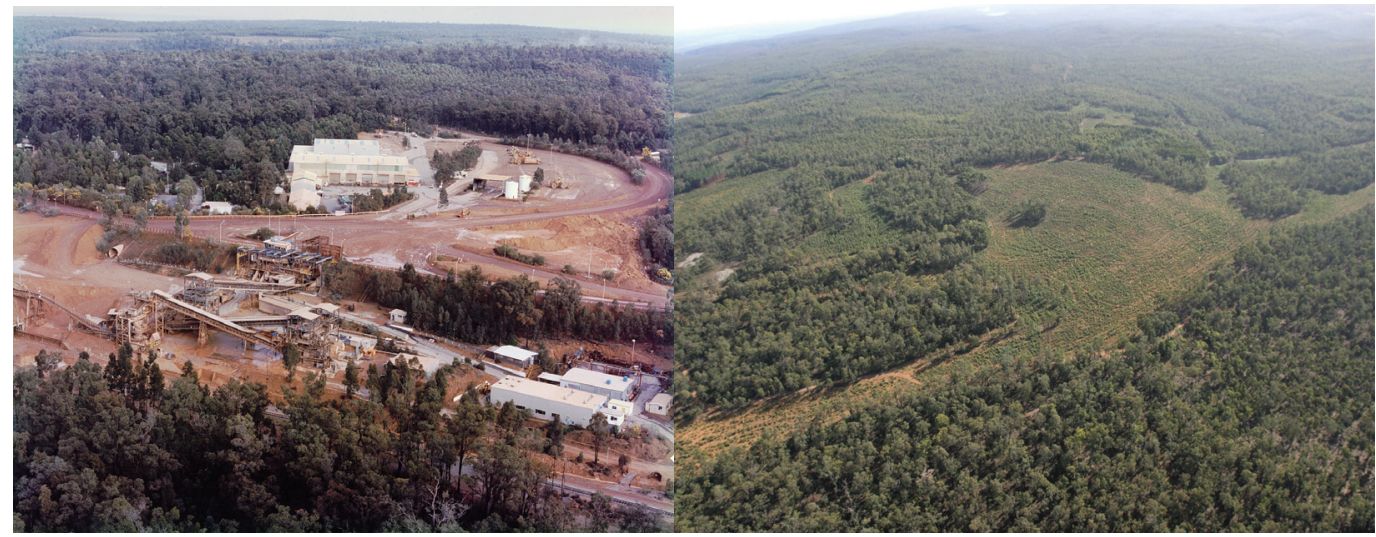

Figure 4 Aerial photo of crusher and workshop area at Jarrahdale during operations (left), and after decommissioning and rehabilitation (right)

\section{$5 \quad$ REMOVAL OF DAM AND STREAM CROSSINGS}

\subsection{Removal of Chandler Dam}

Chandler Dam was the water supply for the Jarrahdale Mine, with a capacity of $450 \mathrm{ml}$ and covering an area of 11.5 ha. Water from the dam was used for dust control on haul roads, washdown of the crusher and workshop areas, and for drinking, toilets and showers. State Government authorities indicated that they had no requirement for the dam to be retained and so it was agreed it would be removed.

After the winter rains had finished in 1999, siphons were used to lower the water level of the dam (Figure 5). The water was siphoned into the stream zone area below the dam. Once the water level was sufficiently low, the dam wall was removed and the fill material placed around the edges of the dam and landscaped to blend into the existing terrain. The edges of the dam were ripped and seeded with tree and understorey species native to the area. Through the middle of the original dam floor, the pre-existing stream zone was established. This consisted of a permanently and a seasonally wet area. These areas were seeded with local species to encourage the establishment of vegetation to minimise the movement of sediment material. Monitoring of turbidity levels was undertaken downstream of the dam for three winters and the results indicated that the rehabilitation of the dam had been successful in minimising mobilisation of sediment. 


\subsection{Removal and Rehabilitation of Haul Road Stream Crossings}

When production ceased at the Jarrahdale Mine in 1998, there were 19 haul road stream crossings that required removal and rehabilitation. These water courses ranged from small seasonal brooks to large streams. A procedure for the rehabilitation of haul road stream crossings was agreed with CALM, Department of Water and the Water Corporation. The aim of the procedure was to ensure that water quality was not impacted during and after the removal of the crossings. The procedure involved:

- Removal of haul roads in stream areas during the latter part of the summer months when stream and underground water levels are at their lowest.

- Removal of all fill material from the stream zone and landscaping the area to blend with the predisturbance stream formation.

- Removal of all geofabric placed on top of the stream bed when the haul road was constructed.

- Placing tea tree brush in the stream zone and on the edges of the stream. The tea tree was held in place by biodegradable mesh onto which rocks and logs were placed (Figure 6). This helped to prevent erosion in the stream area and also encourage the quick establishment of tea tree plants to stabilise the site.

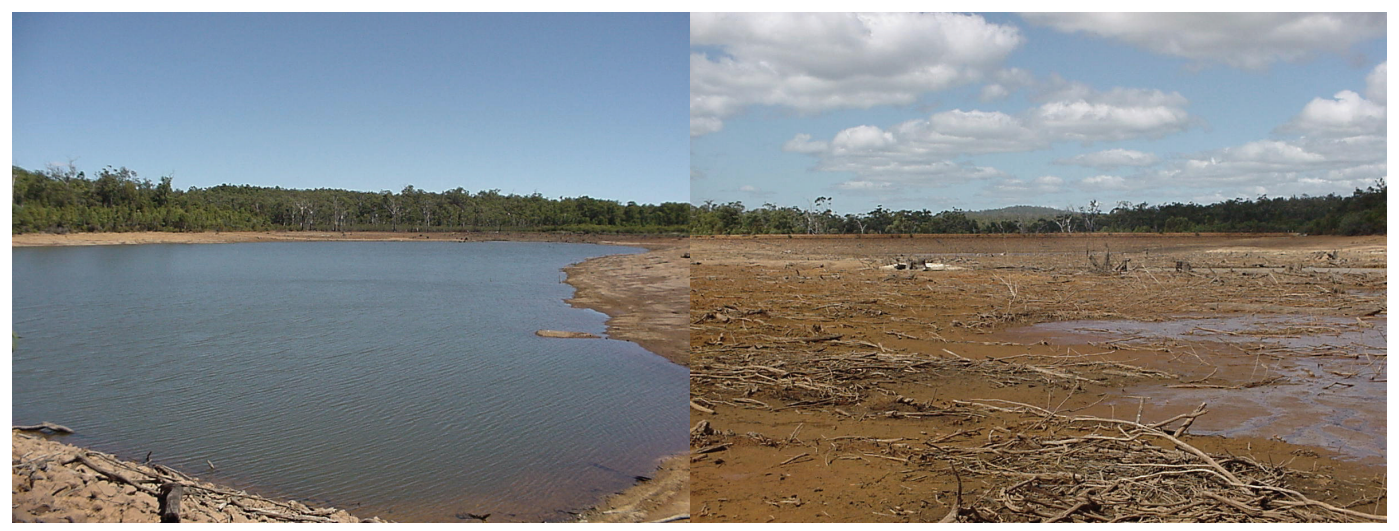

\section{Figure 5 Chandler Dam during siphoning process (left) and at the completion of the process in April 2000 (right)}
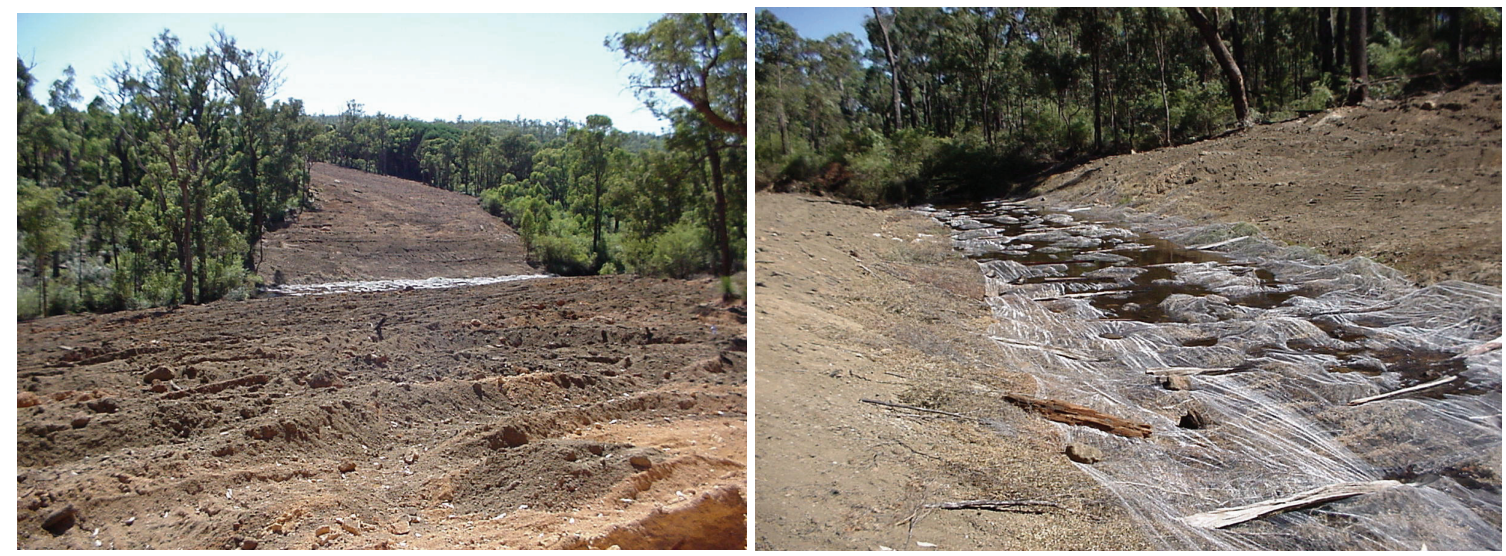

Figure 6 Rehabilitation of a haul road stream crossing: from a distance (left) and closeup (right) 


\section{REMOVAL OF CONTAMINATED MATERIALS}

\subsection{Introduction}

During the life of the Jarrahdale Mine, no processing of ore had occurred on site. The main source of contamination was due to the use and storage of fuel and oils. Only small amounts of chemicals were stored on site for cleaning, and use in the waste water and sewage treatment plants. To ensure that all areas of contamination were identified and remediated, a site specific strategy was developed based on the Australian and New Zealand guidelines for the Assessment and Management of Contaminated Sites (ANZECC/NHMRC, 1992). At that time, there were limited regulatory guidelines in Western Australia for the management of soil contamination. In consultation with various government departments, it was decided that Ecological Investigation Levels (EILs) would be used as the remediation criteria.

\subsection{Assessment and Strategy}

Potential areas of contamination were identified by reviewing the site records detailing the historical storage and reporting of spillages of hydrocarbons. A field survey was also undertaken to identify areas of visual staining by hydrocarbons. The following strategy was developed to remediate contamination that existed on site:

- Remove all visible hydrocarbons in soil or on concrete.

- Use a photoionisation detector (PID) to determine if further material needed to be removed.

- Remove any further material.

- Take validation samples to confirm contamination has been removed or is below EILs.

- Review sample results: if below EILs area classed as remediated; or if the sample was above EILs review impact to environment by leaving in-situ or remove material and re-validate.

\subsection{Removal of Contaminated Material}

All visible contamination and any contamination identified using the PID was removed and placed in a temporary stockpile area for later trucking offsite to an approved disposal location. For soil, all visible material was removed with an excavator. For concrete areas, a rock breaker was used to chip off the contaminated sections to minimise the amount of material requiring offsite disposal. This process was validated by taking samples of the concrete material remaining and testing for Total Recoverable Hydrocarbon (TRH) levels. In all places where staining was chipped away and samples taken, the results were undetectable or below the adopted guidelines.

\section{REHABILITATION OF DISTURBED AREAS}

\subsection{Introduction}

When mining ceased at Jarrahdale in December 1998, there was approximately 630 ha of area to be rehabilitated. This included mined pits, haul roads, infrastructure areas, the access road and the section of railway line owned by Alcoa. Rehabilitation of the site was completed in May 2001. The rehabilitation objective was to establish a self-sustaining jarrah forest ecosystem that maintains or enhances other land-uses such as conservation, timber and water production, recreation and other forest values. To achieve this objective, rehabilitation of all areas was undertaken as per the agreed Alcoa/CALM Working Arrangements (2005-2009) to achieve the completion criteria for areas rehabilitated after 1988 (see below). In recognition of the different rehabilitation prescriptions utilised over the 35 year operational life of Jarrahdale, two sets of completion criteria have been established for sites rehabilitated prior to and after 1988. These are discussed separately below. 


\subsection{Completion Criteria for Areas Rehabilitated after 1988}

Completion criteria have been defined as rehabilitation performance objectives (Grant et al., 2001). They represent milestones in the biophysical processes of rehabilitation that provide a high degree of confidence that a rehabilitated mine site will eventually reach the desired, sustainable state (rehabilitation objective). Industry is looking for criteria that indicate the success of its rehabilitation and enable it to determine when its liability for an area ceases. Governments also want successful rehabilitation to ensure that they are not inheriting an ongoing liability or that a liability will be transferred to private landowners or the next landuser, in the case of public lands (Elliott et al., 1996). Rehabilitation could be considered successful when the site can be managed for its designated land-use without any greater management inputs than other land in the area being used for a similar purpose. Alcoa developed completion criteria for post-1988 rehabilitation through the 1990s, with the regulatory authorities and other stakeholders signing off on these criteria in 1998 (DoIR, 2002). Alcoa defined five broad principles for completion criteria relating to rehabilitated bauxite mines in the jarrah forest namely that the areas meet land-use objectives, are integrated into the landscape, exhibit sustained growth and development, vegetation is as resilient as the jarrah forest and can be integrated with forest management.

These criteria are assessed under five time categories (from planning to $>15$ year old rehabilitation), with intent, guidelines for acceptance, accepted standard and corrective actions identified for each criteria. All rehabilitation completed at Jarrahdale since 1988 was undertaken as per the Alcoa/CALM prescription. The rehabilitation has also been monitored at 9 and 15 months to determine its success against a number of parameters. Since 1998, a staged signoff process had been used at the sites that involves a company officer signing-off at each stage of the rehabilitation that the work has been done to the standard agreed by CALM. Any deviations to these standards and the reasons why are noted, sites are inspected by CALM and re-work is undertaken if required. As a result of these processes, Alcoa was confident that all of the post-1988 rehabilitation met agreed completion criteria.

\section{REVIEW OF OLDER REHABILITATION AREAS}

\subsection{Introduction}

Rehabilitation of mined areas at Jarrahdale commenced in 1966. Early prescriptions, agreed between Alcoa and the State Government, involved planting pine trees with little site preparation. Techniques were developed further through the 1970s, with greater landscaping of pits, return of topsoil and ultimately seeding of an understorey. Non-native eucalypt species were used in many areas up to 1988 , due to the unknown impact that dieback caused by Phytophthora cinnamomi was going to have on the susceptible forest dominant jarrah. Research conducted through the 1980s indicated that jarrah would survive well in rehabilitated areas even if the soil contained the dieback fungus. As a result, only native overstorey species have been used in rehabilitation since 1988. In recognition of the fact that completion criteria cannot be retrospective, a different set of criteria were developed for areas rehabilitated prior to 1988. These criteria were developed using a similar process to the post-1988 criteria and were eventually signed-off in 2002 (DoIR, 2002).

\subsection{Assessment of Pre-1988 Rehabilitation Areas against Completion Criteria}

At the Jarrahdale Mine, there was around 2000 ha of rehabilitation that was completed before 1988. In a number of older areas, pit faces were not landscaped into the surrounding landform, and sumps and contour banks were installed to manage drainage. To ensure that the pre-1988 rehabilitation would achieve the completion criteria, all areas at the Jarrahdale Mine were inspected and assessed. Assessment sheets were developed against the completion criteria and recorded the applied rehabilitation prescription, soil preparation (e.g. scarification or ripping), tree form and crown vigour, understorey cover and legume density, litter accumulation, presence of volunteer species, jarrah presence and stage (e.g. seedling, lignotuber, coppice, sapling pole), approximate stocking rate, extent of remnant infrastructure (e.g. contour banks, pit faces, designed waterways, erosion) and post rehabilitation management. 
The assessment determined whether the site was exhibiting sustained growth and development. If a site received a low score it was reviewed with CALM to determine the need for corrective action and the extent of rework required to improve the site. Re-work prescriptions aimed to favour the re-establishment of jarrah forest species and suppress the re-establishment of non-native species. Areas that did not meet the standards due to the presence of significant infrastructure, such as pit faces, were automatically reviewed with CALM regardless of growth on the site (Figure 7). Following these inspections, a total of 133 ha was identified as requiring further rehabilitation. These areas were rehabilitated according to the post-1988 rehabilitation completion criteria and monitored accordingly. While all re-rehabilitated areas eventually met the appropriate criteria, the quality of the rehabilitation in these areas was uniformly lower than areas being rehabilitated for the first time. This emphasises that further disturbance of rehabilitated areas should be avoided wherever possible as the end result may be even worse than the existing current condition. Remedial action of the existing vegetation rather than complete removal of it should be the preferred option.

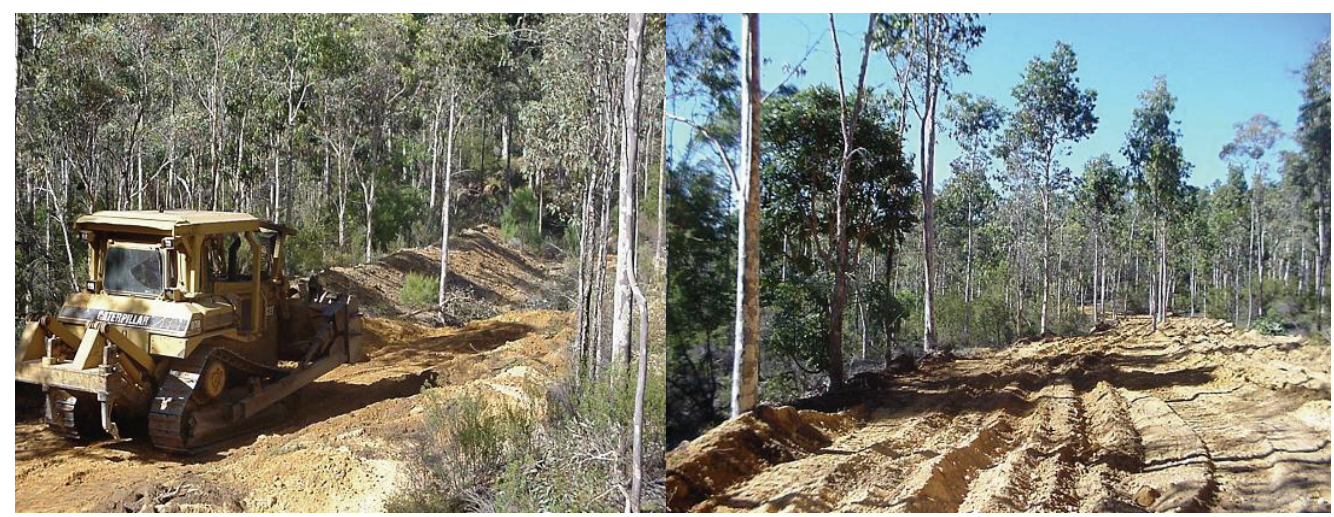

\section{Figure $7 \quad$ Removal of a contour bank from a pre-1988 rehabilitation pit (left) and subsequent re-rehabilitation of the area (right)}

\section{MANAGEMENT OF REHABILITATION}

During the development of Alcoa's completion criteria, the most contentious issues related to the resilience of rehabilitation to further disturbance and the ability to integrate the management of rehabilitated areas with the surrounding unmined forest. CALM undertakes prescribed burning in the majority of jarrah forest on an 8 to 15 year rotation (Burrows, 1994). Furthermore, all the forest surrounding the Jarrahdale Mine has been logged at least once in the past 150 years. In recognition of the need to demonstrate that rehabilitated areas can be managed in association with the surrounding unmined forest, a major research program was instigated in the early 1990 s to investigate the integration of the management of rehabilitated areas with the surrounding unmined forest. Research projects completed over the last 15 years include:

- Effect of prescribed burning on 11-15 year-old pre-1988 rehabilitation (e.g. Grant, 2003a).

- Resilience of 5 and 8 year-old rehabilitation to fire (e.g. Smith, 2001).

- Establishing jarrah in pre-1988 rehabilitation after burning (e.g. Grant, 1997).

- Effect of fire on the nutrient status of pre-1988 and post-1988 rehabilitation (e.g. Morley, 2002; Morley et al., 2003).

- Integration of fire and silvicultural management of pre- and post-1988 rehabilitation (Grant, 2003b).

Based on the first 10 years of research, a review was published in CALM Science (Grant et al., 1998) that also outlined a process for the development of prescriptions for rehabilitation burns. More than 2000 ha of pre- and post-1988 rehabilitation had been burnt to the end of 2005 . The majority of the early burning of rehabilitated areas was for research purposes, but in the last few years areas have been burnt largely for operational reasons.

The major outcomes from the research and monitoring related to the management of rehabilitation that have relevance to completion criteria are the most appropriate fire regime for rehabilitated areas, fire risk assessments and planning, stocking of rehabilitation with fire resilient overstorey species, and integration of 
silvicultural and burning practices. It is a formal requirement that the completion criteria for Alcoa's rehabilitated areas are reviewed every five years. As part of this process, a Fire Working Group with representatives from CALM and Alcoa was established in 2005 to resolve any outstanding issues relating to the fire management of rehabilitated areas. At the time of writing this paper, the report from this group was in final draft form.

\section{CERTIFICATE OF ACCEPTANCE}

Alcoa's completion criteria contained broad guidelines as to how responsibility for an area of rehabilitation would be relinquished and a certificate of acceptance issued, but no detail about how this would be administrated. A detailed process was drafted in 2004 and eventually signed-off by the MMPLG in 2005 (Figure 8). An area containing 975 ha of rehabilitation at the Jarrahdale Mine was identified as the first one to be submitted to the MMPLG to ultimately receive a certificate of acceptance. The Water Corporation is proposing to undertake thinning and burning operations in the rehabilitation and surrounding unmined forest to increase water run-off into the adjacent Wungong Reservoir. This was one of the drivers for putting this particular area up for sign-off. A submission was made to the MMPLG in February 2005 and the first certificate of acceptance for a significant area of mining rehabilitation in Australia was issued in November 2005 (Figure 9).

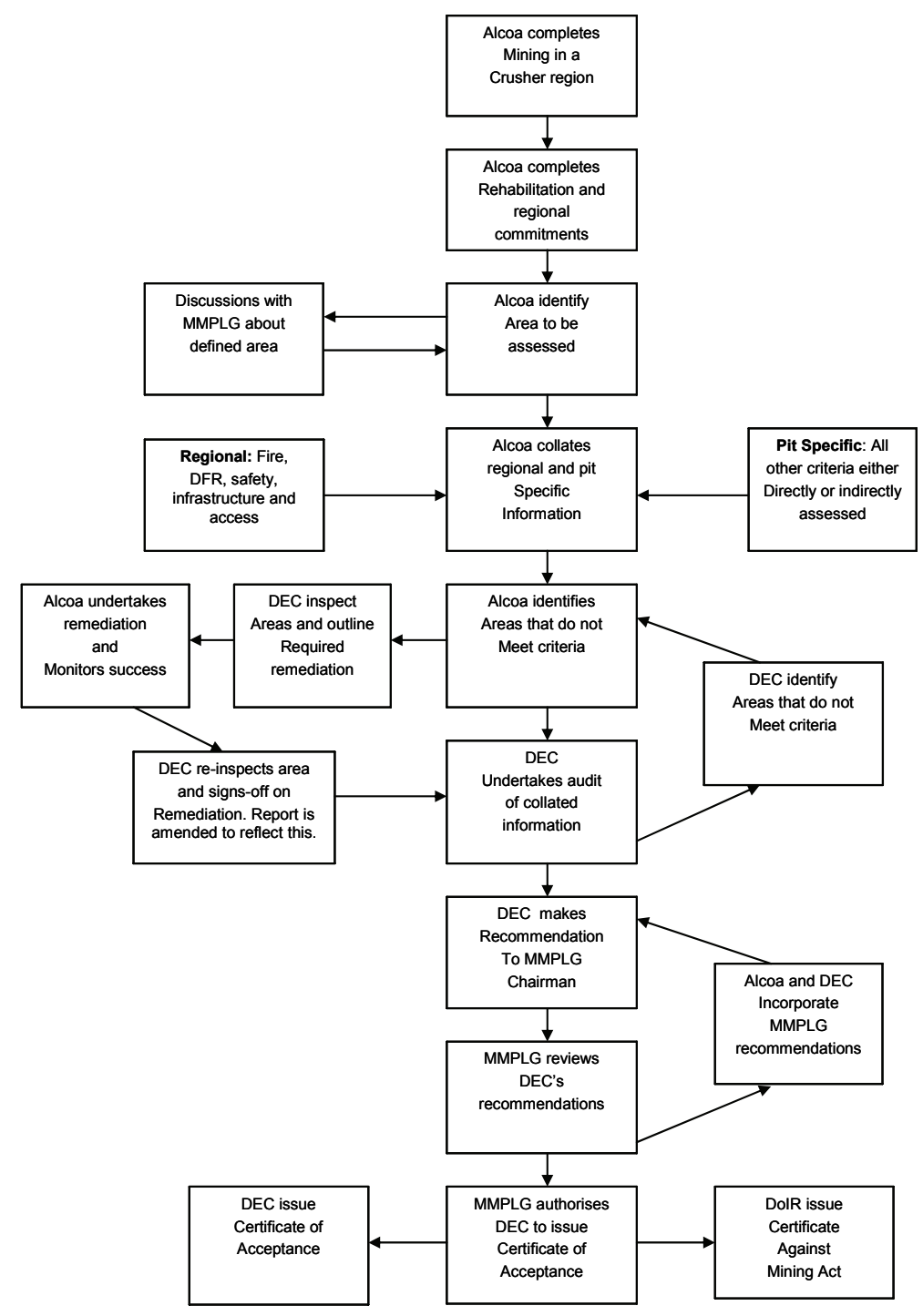

Figure 8 Detailed process for sign-off against completion criteria 


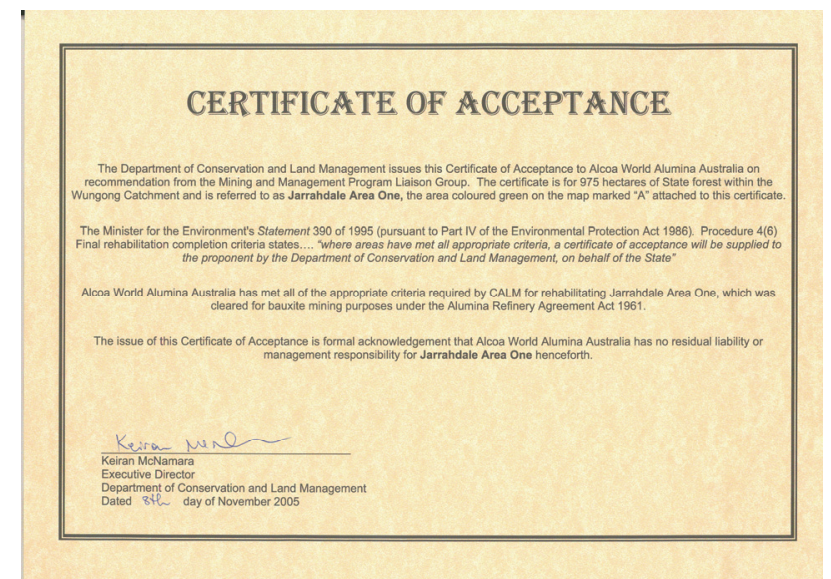

Figure 9 Certificate of acceptance for 975 ha of rehabilitation at the Jarrahdale Mine

\section{ACKNOWLEDGEMENTS}

I would like to acknowledge Samantha Jarvis who supervised the implementation of the Jarrahdale decommissioning plan. The structure of this paper is based on a number of documents that she made a significant contribution to. Louis Bursztyn (Department of Industry and Resources) assisted with the construction of Figure 8. John Gardner and Ian Phillips provided comments on an earlier draft.

\section{REFERENCES}

Alcoa/CALM Working Arrangements for Bauxite Mining Operations (2005-2009) Alcoa World Alumina Australia.

ANZECC/NHMRC (1992) Australian and New Zealand Guidelines for the Assessment and Management of Contaminated Sites. ANZECC, Canberra.

Burrows, N.D. (1994) Experimental development of a fire management model for Jarrah (Eucalyptus marginata Donn ex Sm.) Forest, PhD Thesis, Australian National University.

Department of Industry and Resources (2002) Alcoa World Alumina Australia Darling Range Bauxite Mine Rehabilitation Completion Criteria, DoIR, Perth.

Elliott, P., Gardner, J., Allen, D. and Butcher, G. (1996) Completion criteria for Alcoa of Australia Limited's bauxite mine rehabilitation. 3rd International and the 21st Annual Minerals Council of Australia Environmental Workshop, Minerals Council of Australia, Canberra, pp. 79-89.

Gardner, J. (2001) Rehabilitating bauxite mines to meet land-use objectives: bauxite mining in the jarrah forest of Western Australia, Unasylva 52, pp. 3-8.

Grant, C.D. (1997) Fire ecology in rehabilitated bauxite mines in the Jarrah (Eucalyptus marginata) Forest of southwestern Australia, $\mathrm{PhD}$ Thesis, The University of Western Australia.

Grant, C.D. (2003a) Post-burn vegetation development of rehabilitated bauxite mines in Western Australia, Forest Ecology and Management 186, pp. 147-157.

Grant, C.D. (2003b) Investigating Thinning and Burning Operations in 10-13 Year-old Rehabilitated Bauxite Mines in the Jarrah Forest, Preliminary Unpublished Report, Alcoa World Alumina Australia.

Grant, C.D., Duggin, J., Meek, I. and Lord M. (2001) End point criteria and successional pathways for manganese mining rehabilitation on Groote Eylandt, Northern Territory. $26^{\text {th }}$ Annual Minerals Council of Australia Environmental Workshop, Minerals Council of Australia, Canberra, pp. 1-10.

Grant, C.D., Koch, J.M., Smith, R.D. and Collins, S.J. (1998) A review of prescription burning in rehabilitated bauxite mines in Western Australia, CALM Science 2, pp. 357-371.

Morley, S.C. (2002) The effect of burning and thinning operations on the nutrient status of rehabilitated bauxite mines in the Jarrah Forest, Western Australia, Unpublished Honours Thesis, Murdoch University. 
Morley, S.C., Grant, C.D., Hobbs, R.J. and Cramer, V.A. (2003) Long-term impact of prescribed burning on the nutrient status and fuel loads of rehabilitated bauxite mines in Western Australia, Forest Ecology and Management 190, pp. 227-239.

Smith, M.A. (2001) Vegetation response to fire as an indicator of restoration success after bauxite mining in the jarrah forest of Western Australia, PhD Thesis, The University of Western Australia.

Ward, S.C., Slessar, G.C, Glenister, D.J. and Coffey, P.S. (1996) Environmental resource management practices of Alcoa in southwest Western Australia. In: D. Mulligan (Editor), Environmental Management in the Australian Minerals and Energy Industries - Principles and Practices. UNSW Press, Sydney. 